\title{
Experimental Evidence of Functional Group-Dependent Effects of Tree Diversity on Soil Fungi in Subtropical Forests
}

\author{
Christina Weißbecker ${ }^{1,2 * \dagger}$, Tesfaye Wubet ${ }^{1,3 \dagger}$, Guillaume Lentendu ${ }^{1,4}$, Peter Kühn ${ }^{5}$, \\ Thomas Scholten ${ }^{5}$, Helge Bruelheide ${ }^{3,6}$ and François Buscot ${ }^{1,3}$
}

${ }^{1}$ Department of Soil Ecology, Helmholtz-Centre for Environmental Research - UFZ, Halle, Germany, ${ }^{2}$ Institute of Biology, Leipzig University, Leipzig, Germany, ${ }^{3}$ German Centre for Integrative Biodiversity Research (iDiv) Halle-Jena-Leipzig, Leipzig, Germany, ${ }^{4}$ Department of Ecology, University of Kaiserslautern, Kaiserslautern, Germany, ${ }^{5}$ Chair of Soil Science and Geomorphology, University of Tübingen, Tübingen, Germany, ${ }^{6}$ Institute of Biology, Martin Luther University Halle Wittenberg, Halle, Germany

Deconvoluting the relative contributions made by specific biotic and abiotic drivers to soil fungal community compositions facilitates predictions about the functional responses of ecosystems to environmental changes, such as losses of plant diversity, but it is hindered by the complex interactions involved. Experimental assembly of tree species allows separation of the respective effects of plant community composition (biotic components) and soil properties (abiotic components), enabling much greater statistical power than can be achieved in observational studies. We therefore analyzed these contributions by assessing, via pyrotag sequencing of the internal transcribed spacer (ITS2) rDNA region, fungal communities in young subtropical forest plots included in a large experiment on the effects of tree species richness. Spatial variables and soil properties were the main drivers of soil fungal alpha and beta-diversity, implying strong early-stage environmental filtering and dispersal limitation. Tree related variables, such as tree community composition, significantly affected arbuscular mycorrhizal and pathogen fungal community structure, while differences in tree host species and host abundance affected ectomycorrhizal fungal community composition. At this early stage of the experiment, only a limited amount of carbon inputs (rhizodeposits and leaf litter) was being provided to the ecosystem due to the size of the tree saplings, and persisting legacy effects were observed. We thus expect to find increasing tree related effects on fungal community composition as forest development proceeds.

Keywords: BEF-China, experimental forest, forest biodiversity experiment, fungal functional groups, host preference, metagenomics, mycorrhizal fungi, soil

\section{INTRODUCTION}

Soil fungi are a highly diverse group of organisms (possibly including several million species; Blackwell, 2011; Taylor et al., 2014), providing many ecosystem services such as organic matter decomposition, element cycling, plant nutrition and plant protection (van der Heijden et al., 2015). They can be assigned to functional guilds based on the primary classes of resources they exploit (Nguyen et al., 2016a), and the composition of their communities is governed by multiple, 
strongly interacting abiotic, biotic and spatial variables (Figure 1). Unraveling the relative contributions of these potential drivers to fungal community composition will greatly facilitate predictions about ecosystem functioning in response to environmental changes, particularly reductions in plant diversity.

Land plants and fungi share intimately associated natural histories (Buscot, 2015). From the onset of the colonization of terrestrial habitats, plants have gained crucial support from arbuscular mycorrhizal (AM) fungi (Humphreys et al., 2010), which provide their plant symbionts with substantial proportions of their phosphorus requirements (Smith and Smith, 2011). Saprotrophic fungi evolved to be the most prominent group of microorganisms capable of decomposing complex plant residues (Floudas et al., 2012), and their descendants include ectomycorrhizal (EcM) fungi. The latter mainly decompose nitrogen-rich polymers, and trade nitrogen and micronutrients against photosynthates with their plant symbionts, thereby greatly extending the plants' ability to acquire both mineral and organic soil resources (Bruns and Shefferson, 2004). Pathogenic fungi can substantially impair plant growth and fecundity (Zeilinger et al., 2016), or even destroy large populations of their hosts, but they also play important roles in maintaining plant diversity and mediating plant succession in forest ecosystems (Gilbert, 2002).

In natural ecosystems, biotic and abiotic components often show strong interdependencies as plant communities coevolve with the abiotic soil matrix, and they interact to affect the physico-chemical conditions of the soils (Augusto et al., 2002; Ayres et al., 2009; Condit et al., 2013; Zemunik et al., 2016). Hence in observational studies it is methodologically difficult to assess the contributions made by each specific factor to the development of ecosystems and their responses to environmental changes (Peay et al., 2010; Martínez-García et al., 2015; Schappe et al., 2017). Correlations between biotic and abiotic factors must be taken into account in order to allow inferences about causal relationships underlying community assemblies and

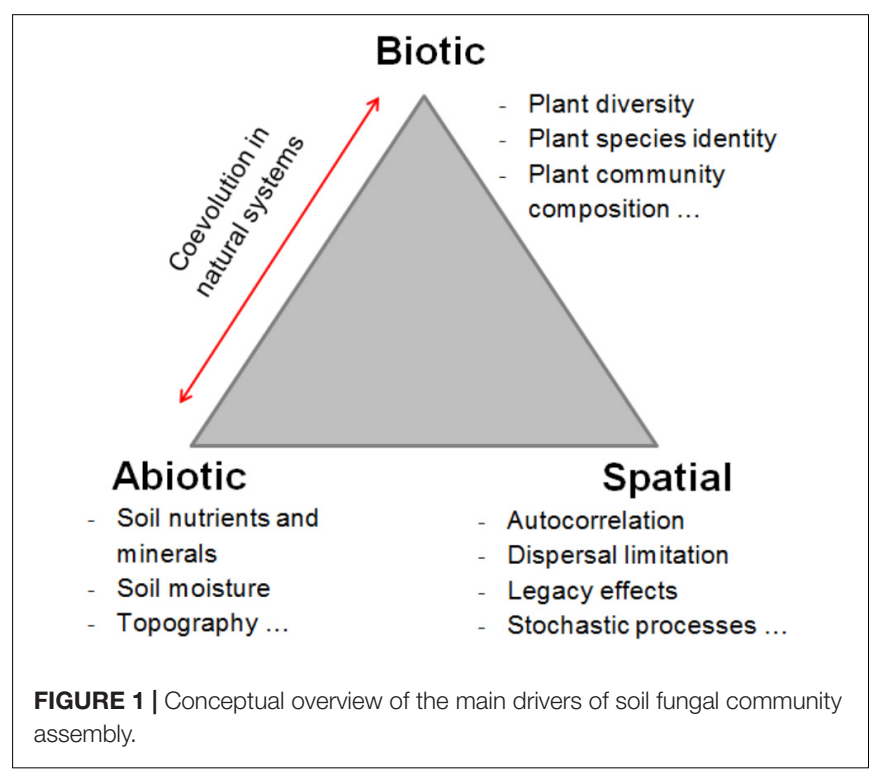

confirmation of insights gained by the multitude of observational studies conducted on regional (e.g., Gao et al., 2015; MartínezGarcía et al., 2015; Urbanova et al., 2015; Tedersoo et al., 2016; Schappe et al., 2017) and global (Tedersoo et al., 2014; Davison et al., 2015; Prober et al., 2015) scales. While Tedersoo et al. (2014) and Prober et al. (2015) postulated that plant and fungal alpha diversity are independent on the global scale (EcM fungi being an exception), several studies have detected significant regional relationships between these variables (tropics: Peay et al., 2013; subtropics: Liang et al., 2015; temperate: Martínez-García et al., 2015; Urbanova et al., 2015; Tedersoo et al., 2016). In terms of community composition, Prober et al. (2015) found a strong correlation between AM fungal and plant beta-diversity in grasslands. Moreover, regional correlations between subtropical tree and AM fungal communities and between tropical tree and non-AM fungal communities have been found by, respectively, Liang et al. (2015) and Schappe et al. (2017). In contrast, EcM fungal communities have been reported to be related to host identity (Ishida et al., 2007; Tedersoo et al., 2008, 2010) and host richness and abundance (Tedersoo et al., 2014), at both host species and higher phylogenetic levels, including host genera (Gao et al., 2013) and families (Tedersoo et al., 2012).

Experimental assembly of host plant species makes it possible to separate the effects of plant community composition (biotic components) and soil properties (abiotic components) on the plant-fungus relationships and associated functional responses of ecosystems. Information about microbial communities in experimental forests will increase in the coming years as many experimental forest platforms have been established recently (Verheyen et al., 2016; Grossman et al., 2018; Paquette et al., 2018). Currently, though, published studies on soil fungal diversity are scarce. To the best of our knowledge, the only published studies on soil fungi conducted in tree biodiversity experiments are those by Nguyen et al. (2016b) and Tedersoo et al. (2016). Nguyen et al. (2016b) focused on relationships among tree and EcM fungal and saprotroph communities in young temperate-boreal forests in the Cloquet IDENT experiment (United States), which includes both American and European tree species. These were assembled in 12 monoculture and 4 six-species mixture plots (replicated four times in a block design, resulting in a total of 64 plots). They detected significant correlations between the beta-diversities of the trees and both the EcM and saprotroph soil fungal communities, but no significant correlations between fungal and tree alpha diversities. Tedersoo et al. (2016) found context-dependent tree diversity and species identity effects on soil fungi among tree experimental forest sites in Finland (the Satakunta experiment) and Estonia. Tree richness was positively correlated with soil fungal groups in Estonia and with EcM fungi in Finland. Communities of soil biota were generally driven by spatial eigenvectors in Finland and soil properties in Estonia. Furthermore, fungal richness was most strongly associated with herb cover and tree basal area.

Here, we extend these findings by reporting the results of a study of fungal communities in plots in a young large-scale subtropical experimental forest in China planted with 1, 2, 4,8 , or 16 native tree species included in a BiodiversityEcosystem Functioning experiment designated BEF-China 
(Bruelheide et al., 2014). We assessed the contributions made by biotic (tree community variables), abiotic (soil properties and topography) and spatial information to the soil fungal richness and community patterns of the four main fungal functional groups: saprotrophic, pathogenic, AM and EcM fungi.

The interplay between plant-driven and abiotic processes and soil fungal communities is likely to vary in strength among fungal functional groups, since they differ in their degree of association with particular plant species. We hypothesized that AM and EcM fungi would show strong, but distinct, correlations with both plant community composition and abiotic soil properties. This is because both groups associate directly with plant roots and the soil matrix, but the ratio of host to symbiont diversity differs between the two types of mycorrhiza (Buscot, 2015). In contrast, necrotrophic parasites and saprotrophic fungi do not depend directly on living plants (Zeilinger et al., 2016), and we expected communities of these groups to be more strongly affected by abiotic soil properties than by the plant community.

\section{MATERIALS AND METHODS}

\section{Sampling Site}

The samples analyzed in this study were collected from plots hosting 1-16 native subtropical tree species at the BEF-China site (Bruelheide et al., 2014), which was established in 2009 on a hillside in Southeast China, Jiangxi Province $\left(29^{\circ} 07^{\prime} 26.0^{\prime \prime} \mathrm{N}\right.$ $\left.117^{\circ} 54^{\prime} 29.0^{\prime \prime} \mathrm{E}\right)$. The climate there is subtropical with warm wet summers and cold dry winters. January and July are the coldest and warmest months, with mean temperatures of 0.4 and $34.2^{\circ} \mathrm{C}$, respectively. The mean annual temperature is $17.4^{\circ} \mathrm{C}$ and mean annual rainfall amounts to $1635 \mathrm{~mm}$ (Yang et al., 2013). Before 2008, the site was in forestry use and hosted an approximately 20-year-old mixed planted stand of trees of the economically important timber species Pinus massoniana (EcM) and Cunninghamia lanceolata (AM), which were clear-cut directly before establishment of the experiment. Monoculture plots of both tree species were present in the BEF-China experimental plantation scheme but were not included in the sampling design of the present study. The planted forest plots are located in the hill altitudinal zone, spanning elevations from 105 to $275 \mathrm{~m}$ a.s.l. and varying considerably in inclination, with an average slope of $25^{\circ}$ (Scholten et al., 2017). The soils are mainly Cambisols and Cambisol derivatives, falling into the reference soil groups Regosols, Cambisols, Acrisols, and Gleysols (IUSS Working Group WRB, 2014), with Cambisols and Regosols on ridges, spurs and crests, Cambisols and Acrisols along slopes and colluvic Cambisols and Gleysols occurring predominantly on foot slopes and in valleys (Scholten et al., 2017). Soil samples collected for this study had $\mathrm{pH}$ values $\left(\mathrm{H}_{2} \mathrm{O}\right)$ of $4.1-5.6$, total nitrogen contents of $0.08-0.31 \%$, carbon to nitrogen ratios of $10-24$, effective cation exchange capacities of $35-91 \mu \mathrm{mol} \mathrm{g}^{-1}$ soil and base saturation values of $6-92 \%$.

A broken-stick design determined the experimental planting schemes of the 31 forest plots investigated here, i.e., the set of 16 native subtropical tree species was repeatedly sub-divided into subsets of eight, four, two, and one species to establish communities with lower diversity levels (Supplementary Figure S1). Each of the 16 tree species was represented once at each diversity level (monocultures, and mixtures of 2, 4, 8, and 16 tree species) and less diverse plots were nested within more diverse plots (Bruelheide et al., 2014). The total tree species pool has equal numbers of AM- and EcM-forming tree species, but lower diversity plots do not necessarily have equal proportions of AM and ECM trees (see Supplementary Figure S1). Each forest plot covers $25.8 \mathrm{~m} \times 25.8 \mathrm{~m}$, and tree species compositions were randomly assigned to plots. In each plot, 400 trees were planted at $1.29 \mathrm{~m}$ spacing, in a regular grid with assigned species being randomly allocated planting positions within the plot. We took samples for this study in October 2011 after the third growing season following planting. At this time the mean total tree height ranged from 52 to $301 \mathrm{~cm}$ depending on tree species (Li et al., 2014). Before sampling for our study, the herb layer was removed by weeding.

\section{Soil Sampling}

In October 2011, we randomly selected five trees per species in each plot (where possible) for sampling of soil in their root zones. Thus we planned to collect five replicate samples of soil in root zones of all 16 tree species at each diversity level (400 samples in total). However, tree mortality prevented collection of six samples in Castanopsis eyrei root zones (five in the four-tree species plot and one in the 16-tree species plot), resulting in a final number of 394 samples.

Soil samples were collected within 7 days. Loose stones and litter were removed from the soil surface and the upper $10 \mathrm{~cm}$ of the mineral soil was sampled, by removing four cores (6 $\mathrm{cm}$ in diameter and $10 \mathrm{~cm}$ deep) at points $20-30 \mathrm{~cm}$ from each selected tree trunk in cardinal compass directions using an auger. The four soil cores obtained from the root zone of each selected tree were mixed, sieved ( $2 \mathrm{~mm}$ mesh size) and homogenized to form a composite soil sample. Two $15 \mathrm{~g}$ subsamples were immediately flash-frozen in liquid nitrogen for molecular analysis. One was stored permanently at $-80^{\circ} \mathrm{C}$ as a backup. The other was freeze-dried for $48 \mathrm{~h}$ and subsequently stored at $-80^{\circ} \mathrm{C}$ in a vacuum-sealed plastic bag containing silica gel prior to transportation to the processing laboratory in Germany. Freeze-dried soil samples were transported by airplane within 4 days, following the recommendation of Weißbecker et al. (2017), and immediately stored at $-80^{\circ} \mathrm{C}$ until required for molecular analysis.

\section{Soil Chemical Analysis}

Soil samples were air-dried, and a $50 \mathrm{~g}$ subsample of each sample was ground with a ball mill. The $\mathrm{pH}$ of sieved samples $(<2 \mathrm{~mm})$ resuspended in $25 \mathrm{ml}$ double-distilled water was measured potentiometrically using a Sentix 81 electrode (WTW, Weilheim, Germany). Total organic carbon $\left(C_{\text {tot }}\right)$ and total nitrogen $\left(N_{\text {tot }}\right)$ contents of ground samples were measured using a Vario El III CN-analyzer (Elementar, Hanau, Germany). Because of the acidic soil conditions, no inorganic carbon was present, so $C_{\text {tot }}$ represented the soil organic carbon content. The sieved soil samples were percolated with an unbuffered $1 \mathrm{M} \mathrm{NH}_{4} \mathrm{Cl}$ solution and the effective cation exchange capacity 
(CEC) of the extracts was measured with a DV 5300 inductively coupled plasma atomic emission spectrometer (PerkinElmer). Soil moisture content was assessed from water loss after freezedrying.

\section{Nucleic Acid Extraction and Multiplexed Amplicon Pyrosequencing}

Microbial DNA was extracted with a PowerSoil ${ }^{\circledR}$ htp 96 Well Soil DNA Isolation Kit, RNA using a PowerSoil ${ }^{\circledR}$ Total RNA Isolation Kit (MO BIO Laboratories Inc., Carlsbad, CA, United States). When using the first of these kits, $0.25 \mathrm{~g}$ samples of freeze-dried soil were extracted twice. When using the second kit, $1 \mathrm{~g}$ samples of freeze-dried soil were re-wetted with $1 \mathrm{ml}$ clean water for 5 min before extraction. After RNA extraction, an RNA PowerSoil ${ }^{\circledR}$ DNA Elution Accessory Kit was used according to the manufacturer's instructions. A negative control with no soil was included in each batch of samples subjected to nucleic acid extraction. Initially, we intended to produce a cDNA dataset based on the extracted RNA as reported by, for example, Baldrian et al. (2012). However, we did not succeed in generating high quality sequences based on cDNA.

The nucleic acid extracts were quantified with a NanoDrop ND-8000 spectrophotometer (Peqlab, Germany). Fungal ITS rDNA amplicon libraries were generated using the fungal-specific ITS1F primer (Gardes and Bruns, 1993) containing Roche 454 pyrosequencing adaptor $\mathrm{B}$, the universal primer ITS4 (White et al., 1990), Roche 454 pyrosequencing adaptor $\mathrm{A}$ and a sample-specific multiplex identifier sequence (MID). The ITS region has been proposed as an universal fungal barcode in metagenomic studies (Schoch et al., 2012) but it has also been reported to lack optimal resolving power for AM fungi (Stockinger et al., 2010). Nevertheless, Berruti et al. (2017) found similar patterns of diversity in AM fungal communities assessed by means of an ITS2 and an AM fungal specific 18S primer pair. The community-structuring effects of location and environment could be resolved correctly by the ITS2 targeting primers. Similar numbers of AM fungal operational taxonomic units (OTUs) have been found in Panamanian rainforest soils using fungal ITS and AM fungus-specific primers (Schappe et al., 2017). We amplified the ITS region sequences by PCR using $50 \mu \mathrm{l}$ reaction mixtures containing 10 ng DNA template in $1 \mu \mathrm{l}$ extraction buffer, $25 \mu \mathrm{l}$ GoTaq Green Master Mix (Promega, Mannheim, Germany) and $1 \mu \mathrm{l}$ of a solution providing $25 \mathrm{pmol}$ of each of the ITS region-specific primers, as described by Wubet et al. (2012). All samples were amplified in triplicate. The PCR replicates were pooled, then purified using a gel extraction kit (Qiagen, Hilden, Germany). DNA concentrations of the purified amplicon products were measured using a Cary Eclipse fluorescence spectrophotometer (Agilent Technologies, Waldbronn, Germany). Equimolar pools of c. 60 sample amplicons were produced and processed according to instructions supplied with the GS FLX+ sequencing kit (Roche, Mannheim, Germany). The sequencing plate was divided into four lanes and one processed amplicon library pool was assigned to each lane. The amplicons were then sequenced by unidirectional pyrosequencing from the ITS4 ends using a Roche GS-FLX+ 454 pyrosequencer (Roche, Mannheim,
Germany) at the Department of Soil Ecology, Helmholtz Centre of Environmental Research (UFZ, Halle, Germany).

\section{Bioinformatics Analysis}

Multiple levels of sequence processing and quality filtering were applied using an in-house metabarcode analysis pipeline for grid engines based mainly on the MOTHUR (version 1.39.5, Schloss et al., 2009) and OBITools (version 1.2.11, Boyer et al., 2016) software suites. Initially, sequences with any barcode mismatches or four primer mismatches were removed. All primer and barcode sequences were discarded. Sequences with any ambiguous bases or homopolymers exceeding eight nucleotides were removed. Flows were denoised and reads were trimmed, using FlowClus (Gaspar and Thomas, 2015), to uniform $360 \mathrm{bp}$ long read fragments spanning the ITS2 and the 5.8S rRNA gene. Chimeric reads were detected and removed from each sample using the UCHIME algorithm as implemented in MOTHUR (Edgar et al., 2011). Dereplicated quality-filtered sequences were sorted by decreasing abundance and clustered into OTUs using the vsearch algorithm (version 2.4.4, Rognes et al., 2016) with a sequence similarity threshold of $97 \%$. Representative (the most abundant) sequences for each OTU were taxonomically assigned based on reference sequences from the UNITE database (version v7_2, Kõljalg et al., 2013) using the naïve Bayesian classifier (Wang et al., 2007), as implemented in MOTHUR, at a consensus threshold of $60 \%$. The sequences identified as fungal were further classified against the full version of the unite.v7_2 database augmented with non-fungal eukaryotic ITS sequences retrieved from GenBank to improve taxonomic annotation and detect nontarget OTUs. In addition, taxonomic assignments of the first 2500 OTUs were manually refined by inspection of the first 15 INSDC database blast search results. Assignments with $E$-values smaller than $\mathrm{e}^{\wedge}-50$ were assumed to be reliable and sequence similarity thresholds of $75,80,85,90$, and $95 \%$ were applied for class, order, family, genus and species classifications, respectively. Putative functions were annotated using the FUNGuild fungal database (version 1.1, Nguyen et al., 2016a). Functional annotations were further refined using information accessible through the APSnet search engine of the American Phytopathological Society ${ }^{1}$ and the MycoBank database (Robert et al., 2013).

\section{Statistical Analysis}

Fungal OTUs with at least four sequence reads were included in the statistical analyses; singletons, doubletons and tripletons were discarded. Non-metric multidimensional scaling (NMDS) ordinations based on 30 random starts were calculated from the abundant fungal OTU dataset (containing at least four sequences) and the original dataset containing all OTUs. Procrustes correlation analysis conducted on both ordinations revealed that fungal community composition was not significantly affected by the presence or absence of rare fungal and potentially artificial OTUs (Procrustes correlation coefficient $=0.9987, p<0.001$ ). Procrustes analysis was carried out applying the protest function (Peres-Neto and Jackson, 2001) of the vegan package (Oksanen et al., 2013). Zhan et al. (2014) found OTUs generated

${ }^{1}$ http://www.apsnet.org 
by pyrosequencing containing more than three sequences to be highly reproducible between sequence runs whereas the reproducibility of OTUs containing three (tripletons), two (doubletons) or one (singletons) sequence read(s) was drastically lower.

Statistical analyses were performed using $\mathrm{R}$ version $3.4 .2(\mathrm{R}$ Core Team, 2014). The data matrices for taxonomic information, environmental variables measured and OTU abundances were merged using the phyloseq package (McMurdie and Holmes, 2013) to facilitate further splitting of the dataset into data pertaining to each of the fungal functional groups under consideration. For the individual fungal functional group analyses, samples were included in the statistical analysis only if an arbitrary read count of 20 (215 samples), 40 (178 samples), 210 (190 samples) and 250 (361 samples) was met for AM, pathogenic, EcM and saprotrophic fungi, respectively. These sequence thresholds correspond to approximately a tenth of the maximum read count for the respective functional groups in a sample. Due to missing tree community data, three samples had to be excluded from the statistical analysis.

We applied linear regression analyses to determine the contributions of tree community variables, soil properties, topography and spatial variables to fungal alpha and beta-diversity relationships. The tree species of the selected tree at each sampling position and its eight nearest neighbors were recorded. The tree community variables assessed included the following: tree species richness, Shannon and Simpson diversity indices of the trees, abundance and richness of EcM and AM trees, tree species identity, their mycorrhizal (ecto vs. arbuscular) type and tree community composition. The abiotic variables included the following soil properties: $\mathrm{pH}$; total nitrogen $\left(N_{\text {tot }}\right)$, total carbon $\left(C_{\text {tot }}\right)$, and moisture contents; $C: N$ ratio; effective cation exchange capacity (CEC); and base saturation (BS); all of these are important indicators of soil fertility (Lincoln et al., 2014; Scholten et al., 2017; Bünemann et al., 2018). In addition, two major topographical variables (altitude and slope) were taken into consideration because the experimental site is located on steep hills. The GPS coordinates of sampling locations were included in the statistical analysis as pairwise sampling distances or spatial eigenvectors.

All analyses were carried out at plot level. For all samples taken from the root zone of the same tree species in a plot, fungal read information was summed for richness analysis, and Hellinger-transformed fungal abundance counts were averaged. Due to the sequence thresholds applied, not all statistical sampling units contained the sequence information from five core replicates (per tree species per plot). While most samples were retained for the analysis of saprotrophic fungi, the number of core replicates was nearly evenly distributed from one to five sampling cores for the remaining fungal groups, AM, EcM and plant pathogenic fungi (Supplementary Table S1).

\section{Fungal Alpha Diversity Analysis}

Species richness information in the fungal count data was derived using the vegan package (Oksanen et al., 2013) and regressed against the square root of the number of reads it was based upon. The resulting fungal richness residuals were included in model calculations. This approach is an alternative method for sequence normalization which is applied to avoid severe loss of valid sequence information (McMurdie and Holmes, 2014; Tedersoo et al., 2014, 2016). We applied a forward model selection procedure to identify significant drivers of fungal alpha diversity. Soil properties, topographic, and tree richness variables (excluding Shannon and Simpson diversity indices) were transformed by the natural logarithm. Coordinates of sampling locations were transformed into principal coordinates of neighborhood matrices (PCNM, Legendre et al., 2009) using the vegan package (Oksanen et al., 2013). The resulting vectors were incorporated into mixed effect models with the variable forest plot identity as a random factor. Correlations of the selected variables were inspected by variance inflation analysis (vif) carried out with the fmsb package using a threshold of 10. We applied a forward model selection procedure with linear mixed-effect models using the lme4 package (Bates et al., 2015) based on the Akaike Information Criterion corrected for small sample sizes (MuMIn package, Barton, 2018). The significance of model parameters was assessed by linear mixed effect models using the nlme package (Pinheiro et al., 2017) followed by Analysis of Variance (ANOVA) type II tests implemented in the car package (Fox and Weisberg, 2011). Shapiro-Wilk tests were applied to confirm that model residuals met normal distribution assumptions. The VarCorr function of the lme4 package was applied to derive the extent to which fungal richness variation was attributable to the random factor forest plot. Explained variance was partitioned to fixed effect factors using the hier.part package (Walsh and MacNally, 2013). The conditional and marginal coefficients of determination for the mixed effect models were calculated using the MuMIn package (Barton, 2018). The marginal coefficients of determination represent the amount of variance explained by the fixed factors while the conditional coefficients of determination indicate the amount of variance explained by both fixed and random factors (Nakagawa et al., 2013).

\section{Fungal Beta-Diversity Analysis}

Beta-diversity values for the fungal and tree communities were calculated in terms of pairwise Bray-Curtis dissimilarities based on averaged (per tree species per plot) Hellinger-transformed abundance counts, representing percentage differences in community composition (Legendre and De Cáceres, 2013). Tree community abundance counts were based on the sampled trees and their eight neighboring tree individuals. Geographic distances between sampling locations, soil properties and topographic variables were standardized by natural logarithm transformation and averaged data were transformed to Euclidean distances.

To identify the environmental variables that explained the most fungal beta-diversity, multiple regressions of distance matrices were applied using the MRM function in the ecodist package (Goslee and Urban, 2007). The identity of forest plots was included as a fixed factor to account for the differences in pairwise sample comparisons within and between plots. Only variables showing significant correlation with fungal beta-diversity in partial Mantel tests after accounting for 
variations in geographical distances between sampling locations were considered for multiple regression analysis. Furthermore, variables were excluded if they had a variance inflation factor (vif) greater than 10, calculated using the vif function in the fmsb package (Nakazawa, 2014). Best subset model selection was carried out to identify the parameters that best explained fungal community turnover. The complete list of best model subsets is shown in Supplementary Tables S4-S7. The percentages of explained variance contributed by the remaining variables were calculated using the varpart function in the vegan package (Oksanen et al., 2013).

\section{RESULTS}

\section{Fungal Taxonomic Assignment}

Pyrosequencing generated 1,155,299 raw sequences in total from the 394 soil samples collected. Clusters of least four of the 737,907 reads that passed the quality filtering were assigned to 5,665 fungal OTUs. Rarefaction curves for each fungal functional group investigated are available in Supplementary Figure S2. In total, 72,56 , and $49 \%$ of the fungal OTUs were classified at the order, family and genus levels, respectively.

We could assign $54 \%$ of the fungal OTUs to a functional group: 31\% (1,768 OTUs), 7\% (410 OTUs), 5\% (320 OTUs), and 5\% (310 OTUs) to saprotrophic, EcM, AM, and pathogenic fungi, respectively (Supplementary Figure S3). On the basis of the OTU numbers, saprotrophic fungi were predominantly Ascomycota (57\%), followed by Basidiomycota (37\%), Mucoromycota (5\%) and Chytridiomycota (1\%). Agaricales was the most diverse order of saprotrophic fungi, accounting for about $20 \%$ of the OTUs (Supplementary Table S2). Pathogenic fungi were predominantly plant pathogens (76\%), followed by mycoparasites (11\%) and animal parasites (11\%). This group was strongly dominated by Ascomycota ( $87 \%$ of the OTUs), followed by Basidiomycota (10\%) and Chytridiomycota (2\%). The five most diverse orders of pathogenic fungi were the Capnodiales (26\%), Pleosporales (14\%), Hypocreales (12\%), and Cantharellales (5\%, Supplementary Table S3). AM fungi, which are monophyletic Glomeromycota, were clearly dominated by members of the order Glomerales (76\% of the OTUs), followed by Archaeosporales (10\%), Diversisporales (4\%) and Paraglomerales (4\%). EcM fungi were almost completely made up of Basidiomycota (86\% of the OTUs) and Ascomycota (13\%). The most diverse orders of these fungi were Agaricales (24\%) and Thelephorales (22\%).

\section{Effects of Spatial, Soil Property and Tree Diversity Variables on Soil Fungal Alpha Diversity}

Mean numbers of saprotrophic, pathogenic, AM and EcM fungal species per tree species within a forest plot were 78, 20, 14, and 9 , respectively. The relative abundances of EcM fungal sequences were greater in the rooting zones of EcM-forming tree species than in those of AM-forming trees, especially in the tree monocultures (Figure 2). Linear regression analysis of fungal richness residuals and tree alpha diversity (Simpson indices) revealed no significant correlations (Figure 3). For the four fungal groups investigated, the final models selected by the forward selection procedure did not include any tree richness related variables (Table 1). In total, spatial variables and soil properties explained 75, 53, 46, and 44\% of AM, saprotrophic, EcM and pathogenic fungal richness residual variance, respectively. Thus about $28-57 \%$ of the variation in fungal richness remained unexplained. Most of the explained variance of the fungal richness residuals was attributable to the PCNM spatial eigenvectors: 47, 27, 26, and 18\% for AM, EcM, saprotrophic and pathogenic fungi, respectively. Of the soil properties tested, $N_{\text {tot }}$ contributed significantly to the explained variation in saprotrophic fungal richness residuals (8\%), soil water content to EcM fungal (16\%) and soil water content, slope and effective cation exchange capacity to AM fungal richness residuals (25\%). The residual richness of pathogenic fungi was correlated only with the spatial PCNM eigenvectors. The variable forest plot, which was included as a random factor in the linear mixed effect models, contributed strongly to the total amount of variance explained by the final models for saprotrophic (17\%) and pathogenic fungi (13\%). It did not affect the model strength for the mycorrhizal fungi richness residuals.

\section{Effects of Differences in Spatial, Soil Property and Tree Community Variables on Soil Fungal Community Structure}

Partial Mantel tests, after accounting for differences in geographic distances between samples, showed that at least one of the tree community variables investigated was significantly correlated with differences in pathogenic, AM and EcM fungal community structure (Table 2). The correlation between tree and saprotrophic community composition was close to the Bonferroni-corrected $\alpha=0.05$ significance level. Differences in AM fungal and pathogen community structure were significantly correlated with tree community composition. EcM fungal community structure was significantly correlated with sample tree identity, sample tree mycorrhiza type (EcM vs. AM), EcM tree abundance and EcM tree richness.

Scatterplots of pairwise Bray-Curtis dissimilarities showing correlations between tree beta-diversity and that of the specific fungal groups differed visibly (Figure 4). Saprotrophic fungal communities showed the least community turnover of all fungal groups, partly overlapping throughout the study site as the dissimilarity value for all pairwise community comparisons was $<1$ (which would represent $100 \%$ community dissimilarity). Community turnover within forest plots was much smaller than that between forest plots. There was no detectable trend in saprotroph community turnover associated with tree community composition. AM and pathogen fungal communities showed less pronounced separation of withinand between-forest plot community comparisons, implying some correlation with tree community structure. Strongly differing fungal communities were detected in some comparisons of soil samples from plots with $\geq 30 \%$ differences in tree community composition. EcM fungi formed very distinct 

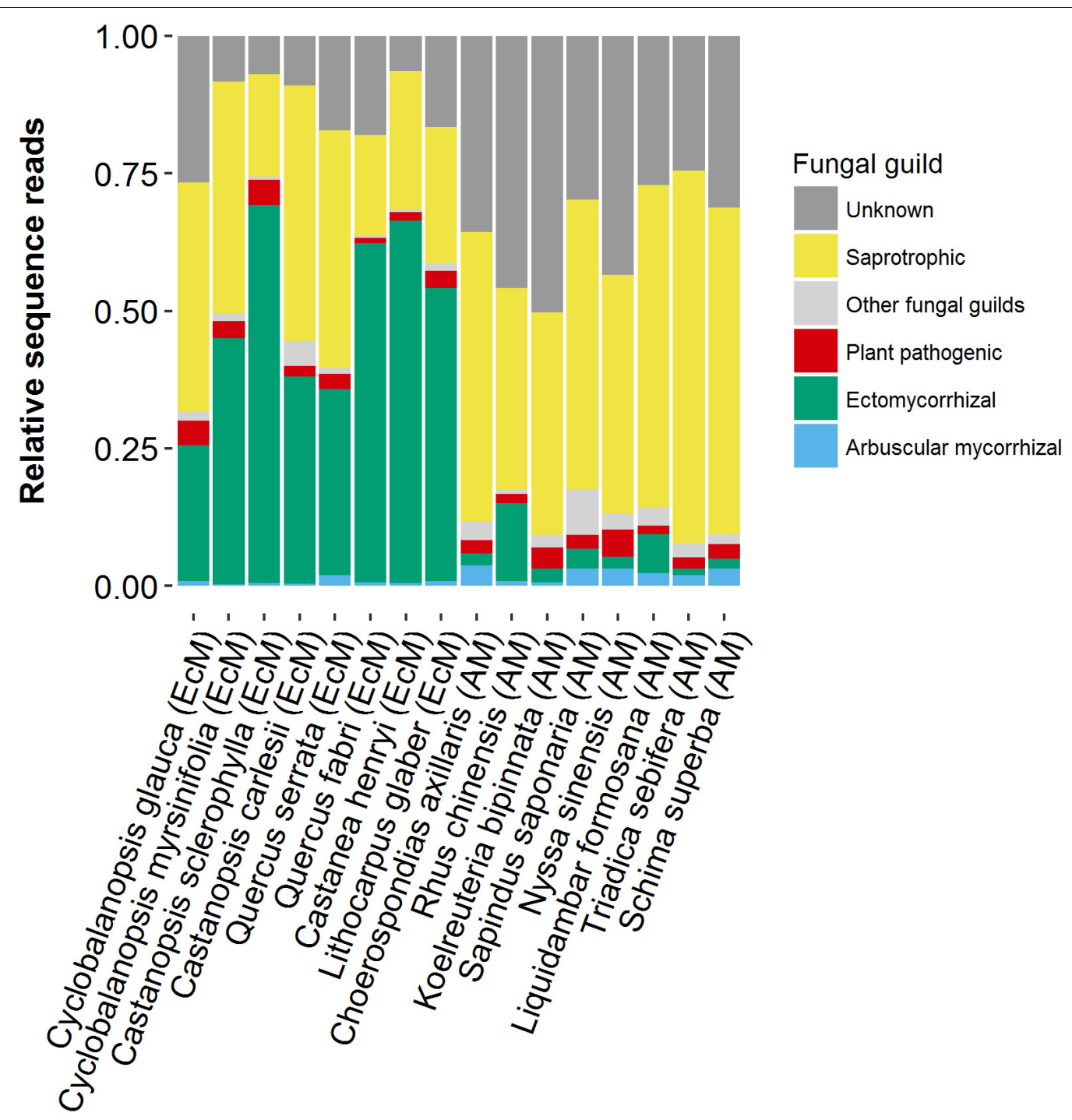

Tree species monocultures

FIGURE 2 | Relative abundances of fungal functional groups in tree monocultures. The mycorrhizal type (EcM or AM) of each tree species is indicated in brackets. Atypically high numbers of EcM fungal sequences were found in two and one of the five replicates of Liquidambar formosana and Sapindus saponaria rooting zone soil samples, respectively (10-fold higher than in the other replicates). These numbers are not displayed in this graphic, but they were included in the statistical analyses.

communities and many pairwise sample comparisons showed no overlap of fungal species. EcM fungal communities showed the highest pairwise community dissimilarities of the four functional groups, with a mean Bray-Curtis dissimilarity of 0.89 , followed by $0.78,0.74$, and 0.69 for AM, pathogenic and saprotrophic fungal communities, respectively. However, EcM fungal communities also showed the highest overlap of two sampled communities of a fungal functional group (approximately $80 \%$ EcM fungal community similarity). Tree communities with differences in composition as low as $13 \%$ had non-overlapping EcM fungal communities. There were no indications of any correlation between EcM fungal and tree community composition.
Following partial Mantel test analysis we selected the best model subsets for identifying the parameters that best explained differences in fungal community structure (Table 3). Abiotic soil properties explained the most variance in saprotrophic, pathogenic and AM community composition. The relevant abiotic variables for saprotroph community turnover were soil total carbon amount, carbon to nitrogen ratio, effective cation exchange capacity, base saturation and soil water content. Carbon to nitrogen ratio was also included in the final models of pathogenic and AM fungal community structure; in addition the latter model contained the abiotic soil properties $\mathrm{pH}$ and effective cation exchange capacity. The influence of tree community variables on fungal species turnover was 


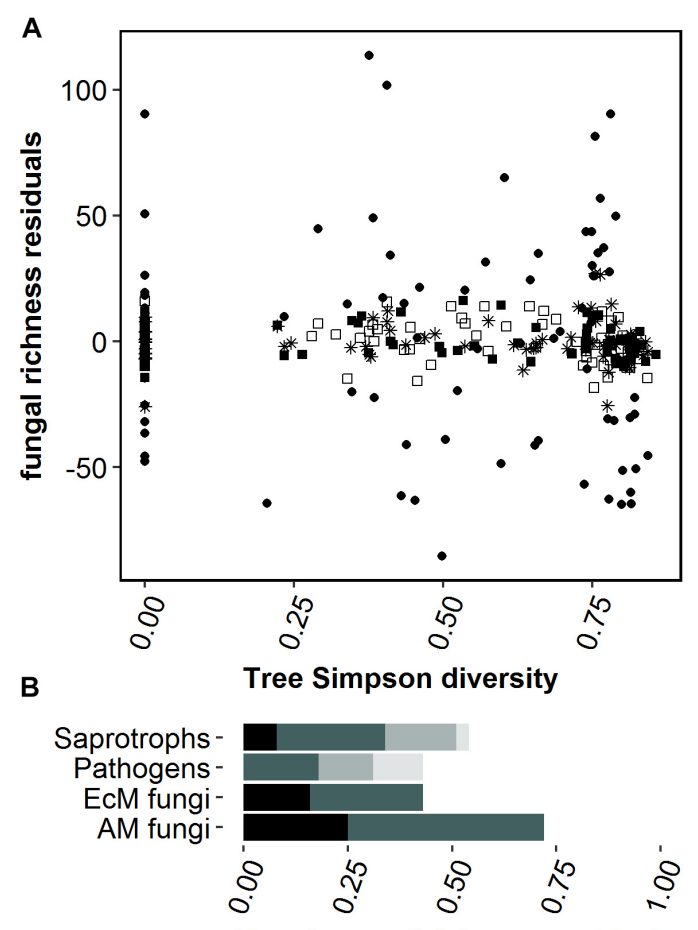

C

$\%$ variance of richness residuals

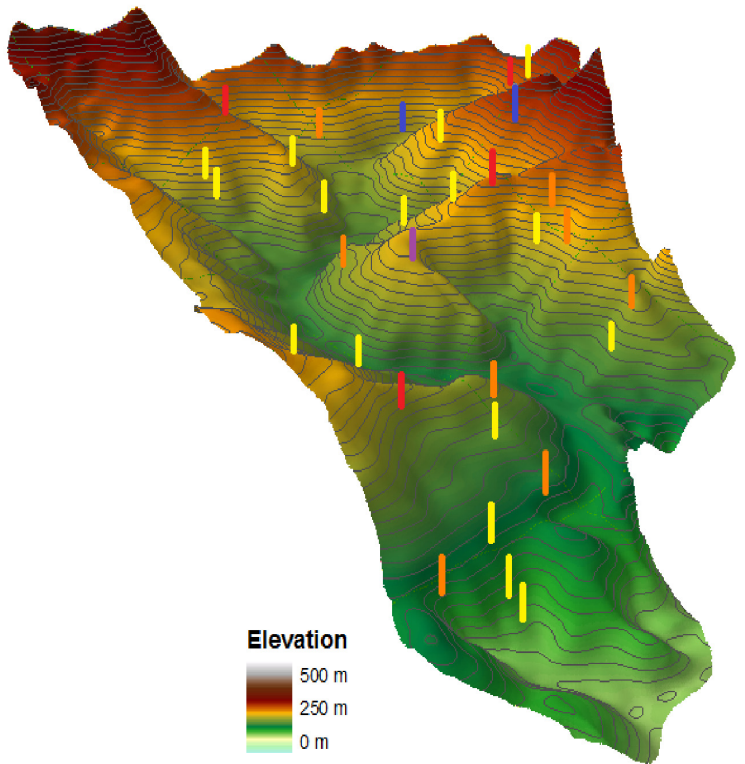

FIGURE 3 | Correlation of fungal richness residuals with tree diversity (A). The scatterplots show residuals of saprotrophic (closed circles), pathogenic (star), ectomycorrhizal (filled squares) and arbuscular mycorrhizal (open squares) fungal richness. Bar plots (B) show contributions of the following abiotic and spatial variables to variations in fungal richness, in decreasing intensity of shading: soil chemistry, geographical principal component neighborhood matrix eigenvectors, forest plot and the joint contribution of the last two factors. The three-dimensional elevation map (C) of the study area highlights the locations of forest plots, with color coding indicating the diversity levels of monocultures (yellow), two-species mixtures (orange), four-species mixtures (red), eight-species mixtures (blue), and 16-species mixture (purple).

TABLE 1 | Final model explaining fungal richness residuals in correlations of saprotrophic, pathogenic, ectomycorrhizal and arbuscular mycorrhizal fungi as functions of spatial, environmental and tree diversity variables.

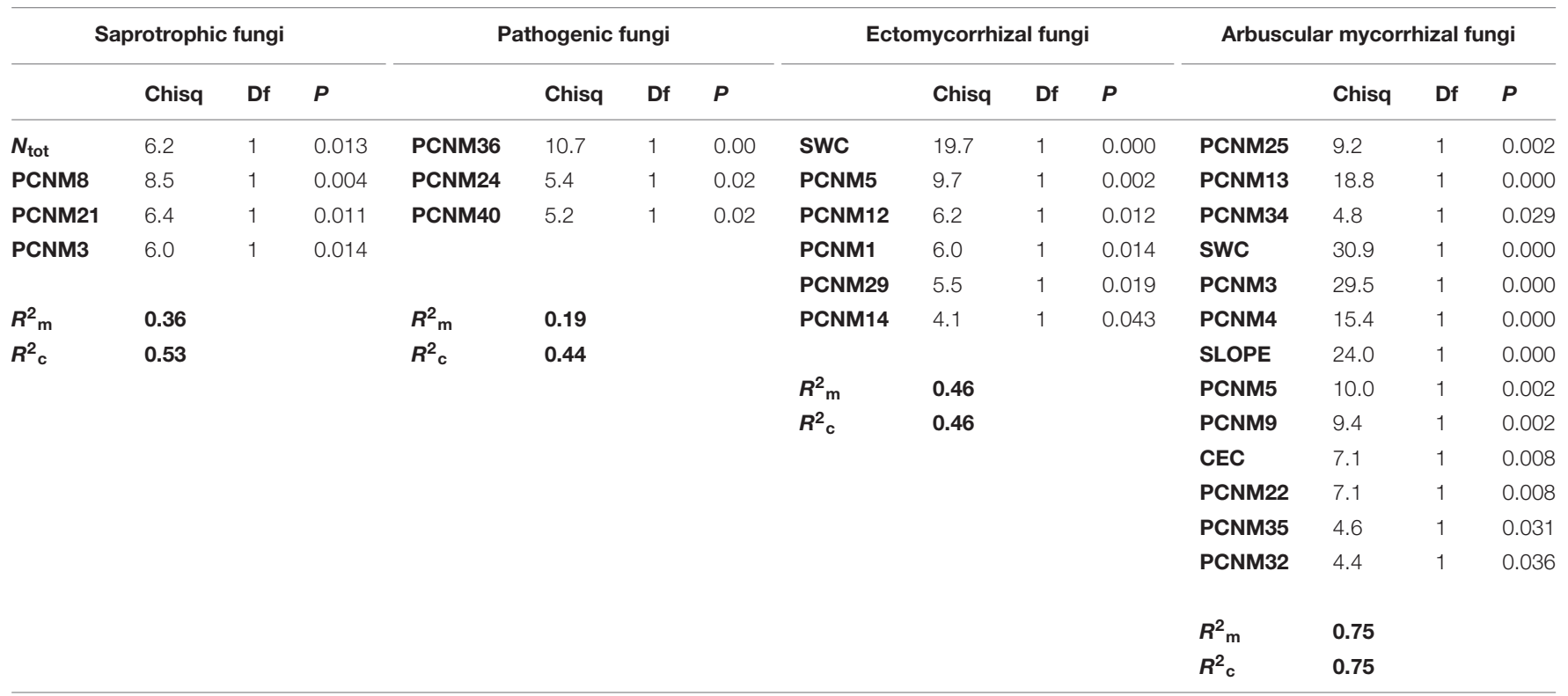

SWC, soil water content; CEC, effective cation exchange capacity; PCNM, Principal Component Neighborhood Matrices of geographical sampling locations. Linear mixed effect models include experimental forest plot as a random factor. Values reported are the marginal amounts of explained variance $\left(R^{2} \mathrm{~m}\right)$ attributed to the fixed variables only and the conditional amount of explained variance $\left(R^{2}{ }_{c}\right)$ attributed to the summed contributions of fixed and random factors (forest plot). 
TABLE 2 | Partial Mantel correlations, after accounting for dissimilarities in geographic location, of fungal and environmental as well as tree community dissimilarities for the fungal functional groups indicated.

\begin{tabular}{|c|c|c|c|c|c|c|c|c|c|}
\hline & \multirow[b]{2}{*}{ Variable } & \multicolumn{2}{|c|}{ Saprotrophic fungi } & \multicolumn{2}{|c|}{ Pathogenic fungi } & \multicolumn{2}{|c|}{ AM fungi } & \multicolumn{2}{|c|}{ EcM fungi } \\
\hline & & $\boldsymbol{R}$ & $\boldsymbol{P}$ & $\boldsymbol{R}$ & $P$ & $\boldsymbol{R}$ & $\boldsymbol{P}$ & $\boldsymbol{R}$ & $P$ \\
\hline (1) & Forest plot & 0.21 & 0.0001 & 0.16 & 0.0001 & 0.14 & 0.0001 & 0.16 & 0.0001 \\
\hline (2) & Tree community composition & 0.11 & 0.0024 & 0.22 & 0.0001 & 0.15 & 0.0003 & 0.07 & 0.0292 \\
\hline (3) & Tree species identity & 0.01 & 0.1668 & 0.02 & 0.0738 & 0.03 & 0.0492 & 0.13 & 0.0001 \\
\hline (4) & Sample tree AM/EcM type & 0.02 & 0.0677 & 0.00 & 0.306 & 0.03 & 0.0729 & 0.32 & 0.0001 \\
\hline (5) & Tree richness & 0.00 & 0.8481 & 0.03 & 0.1732 & 0.01 & 0.3838 & 0.05 & 0.0901 \\
\hline (6) & Tree Shannon diversity & 0.00 & 0.8736 & 0.03 & 0.1685 & 0.01 & 0.3561 & 0.05 & 0.0885 \\
\hline (7) & Tree Simpson diversity & 0.00 & 0.8903 & 0.04 & 0.162 & 0.03 & 0.2673 & 0.03 & 0.2373 \\
\hline (8) & EcM tree abundance & 0.00 & 0.5179 & 0.05 & 0.1991 & 0.00 & 0.7535 & 0.21 & 0.0004 \\
\hline (9) & AM tree abundance & 0.00 & 0.5649 & 0.02 & 0.3418 & 0.08 & 0.0905 & 0.06 & 0.0863 \\
\hline (10) & EcM tree richness & 0.00 & 0.7971 & 0.06 & 0.1652 & 0.00 & 0.9385 & 0.19 & 0.0003 \\
\hline (11) & AM tree richness & 0.00 & 0.6219 & 0.00 & 0.4885 & 0.00 & 0.4695 & 0.00 & 0.1234 \\
\hline (12) & $\mathrm{pH}\left(\mathrm{H}_{2} \mathrm{O}\right)$ & 0.38 & 0.0001 & 0.20 & 0.0028 & 0.41 & 0.0001 & 0.12 & 0.0141 \\
\hline (13) & $N_{\text {tot }}$ & 0.13 & 0.0214 & 0.06 & 0.1714 & 0.08 & 0.1225 & 0.07 & 0.0979 \\
\hline (14) & $C_{\text {tot }}$ & 0.22 & 0.0001 & 0.19 & 0.0016 & 0.26 & 0.0004 & 0.09 & 0.0418 \\
\hline (15) & $C: N$ ratio & 0.41 & 0.0001 & 0.31 & 0.0001 & 0.40 & 0.0001 & 0.08 & 0.0497 \\
\hline (16) & $\mathrm{BS}$ & 0.35 & 0.0001 & 0.19 & 0.0038 & 0.35 & 0.0001 & 0.04 & 0.2378 \\
\hline (17) & CEC & 0.23 & 0.0001 & 0.07 & 0.0956 & 0.26 & 0.0002 & 0.11 & 0.0272 \\
\hline (18) & Soil water content & 0.18 & 0.0005 & 0.18 & 0.0092 & 0.12 & 0.0368 & 0.09 & 0.0331 \\
\hline (19) & Altitude & 0.00 & 0.96 & 0.00 & 0.8169 & 0.00 & 0.644 & 0.00 & 0.948 \\
\hline (20) & Slope & 0.07 & 0.0798 & 0.00 & 0.4638 & 0.06 & 0.1671 & 0.00 & 0.6141 \\
\hline
\end{tabular}

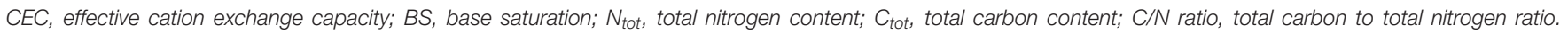

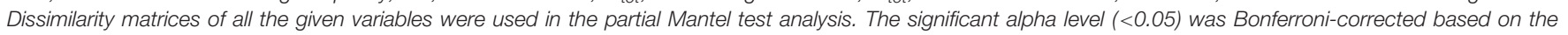
number of variables tested $(\alpha<0.0023$ ). Bolded values indicate variables that are significantly correlated.

strongly dependent on the fungal functional group investigated. Collectively, the tree-related variables that were found to be significant in the partial Mantel tests explained $11 \%$ of differences in EcM fungal community structure in the final MRM models. Although significant correlations were detected between tree community dissimilarity and both pathogenic and AM fungal community structure, the percentages of variance these correlations explained were very low: 5 and 2\%, respectively. Spatial variables explained a large part of saprotroph and EcM fungal community variation but were only negligibly correlated with pathogenic and AM fungal community composition. Thus all of the three variable classes, biotic, abiotic and spatial variables, showed important correlations with soil fungal community structure, but the extent to which they did so greatly varied among the functional fungal groups. The best model subsets explained 54, 43, 26, and 23\% of differences in saprotrophic, AM, EcM and pathogenic fungal community structure, respectively, leaving a large part of fungal community variation unexplained.

\section{DISCUSSION}

Soil fungi are a diverse (Blackwell, 2011; Taylor et al., 2014) and very heterogeneous group of organisms (Nguyen et al., 2016a). Our unprecedented study comprised the systematic analysis of four main fungal functional subgroups: saprotrophic, plant pathogenic, AM and EcM fungi. The subtropics constitute a zone of transition from temperate forests dominated by ectomycorrhizal symbiosis to tropical forests dominated by arbuscular mycorrhizal symbiosis. The subtropics thus harbor a high diversity of evergreen and deciduous tree species, and the number of AM and EcM forming trees occurring there is balanced, enabling the investigation of a broad range of fungal functional groups (Toju et al., 2014). Furthermore, the availability of a large-scale experimental assembly of native subtropical tree species enabled the quantification of the independent individual contributions made by tree community structure and soil properties and topography to soil fungal assembly. In contrast, tree community composition and richness (biotic variables) and soil properties (abiotic variables) are intermingled in naturally evolved forests. Our results provide evidence for a highly differentiated pattern in fungal-tree and fungal-environment (abiotic) relationships for all the fungal groups investigated. As expected, EcM fungal community assembly showed the strongest correlation with tree community variables, while saprotroph community assembly was driven only by abiotic spatial variables and soil properties. Against our expectations, AM fungal and tree community structure were significantly but weakly related. Fungal richness was not correlated with any of the tree community variables assessed. The strong influence of spatial variables and abiotic soil properties on fungal community assembly implies considerable early-stage environmental filtering and dispersal limitation. 

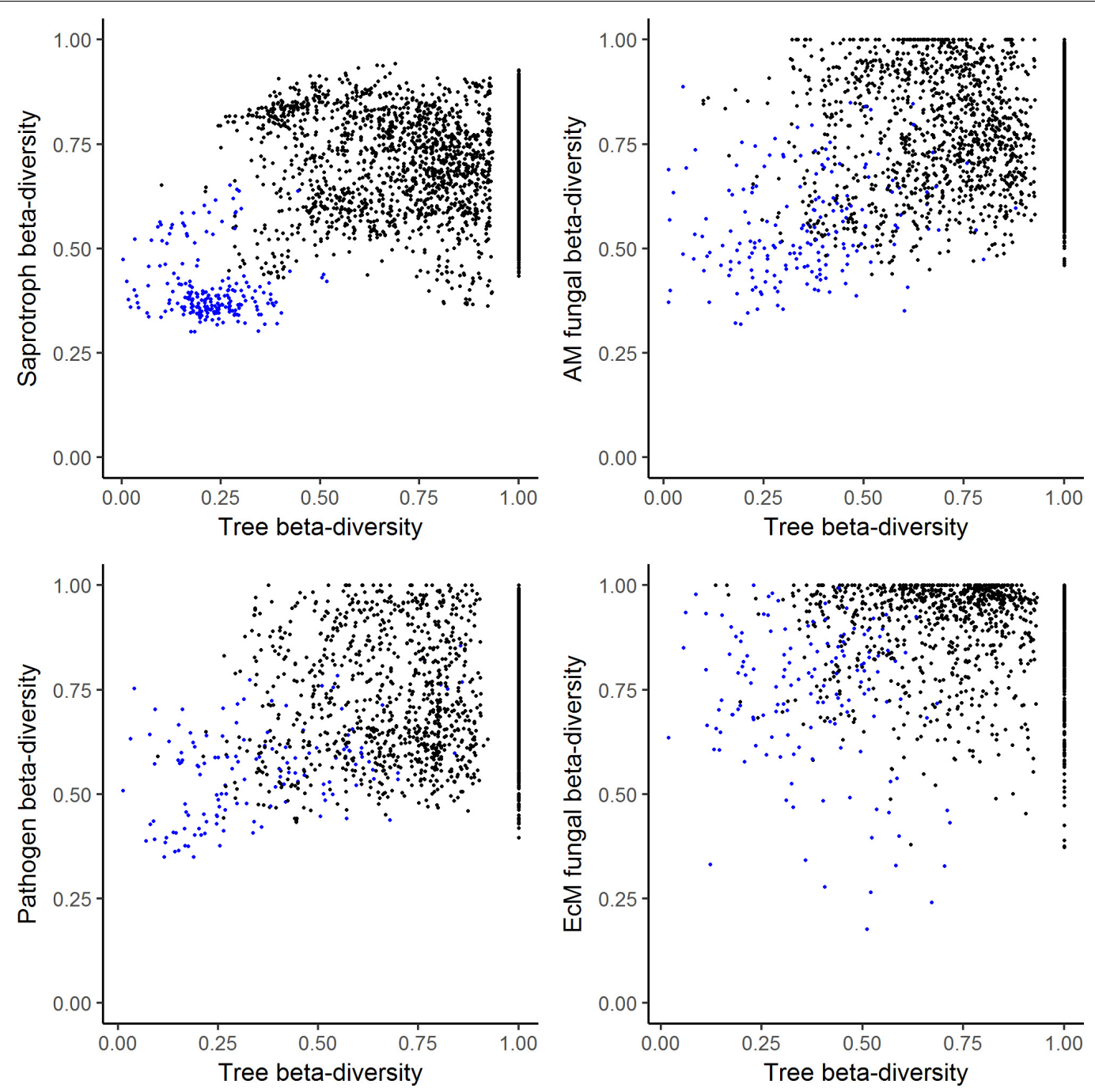

FIGURE 4 | Relationship between fungal and tree beta-diversity (expressed as pairwise Bray-Curtis dissimilarities). Black circles show results of across forest plot comparisons and blue circles results of within forest plot comparisons (between differing tree species).

\section{Spatial Variables and Abiotic Soil Properties Contributed to Variation in Fungal Richness}

It was predominantly spatial variables, but also soil properties, that influenced fungal richness. The strong spatial effects might result from variations in recent fungal spore inputs, and unknown legacy effects of the vegetation previously at the site may also contribute. Such effects would be extremely difficult to quantify. The experimental site was directly surrounded by forest plantations to the north, west and east. Inputs from these forests would depend on multiple factors, including their composition, maturity and climatic factors. Similarly, the two tree species that were dominant in the clear-cut forest plantation are knownCunninghamia lanceolata (AM) and Pinus massoniana (EcM)but they were randomly distributed and the exact previous positions of these species and other minor components of the previous stands were not recorded.
Abiotic soil properties moderately impacted the variation in fungal richness of saprotrophic (8\%, total nitrogen content), EcM (16\%, soil water content) and AM fungi (25\%, soil water content, slope, effective cation exchange capacity). The significant effect of soil nitrogen on saprotroph richness could be explained by the major limitation of this soil resource in our forests, where plant-microbial competition for soil nitrogen was reported previously (Pei et al., 2016). AM fungi depend on carbon provided by their host plants. The link between AM fungal richness and the two abiotic variables slope and effective cation exchange capacity could be related to this dependency. At our experimental site, slope was one of the main predictors of soil fertility (Scholten et al., 2017) which might impact tree productivity, thereby influencing the amount of rhizodeposition by host plants. Cation exchange capacity can be attributed mainly to soil aluminum content and aluminum negatively affects tree height (Scholten et al., 2017). Aluminum stress has been reported 
TABLE 3 | Best subsets of environmental dissimilarity models explaining fungal beta-diversity.

\begin{tabular}{|c|c|c|c|c|c|c|c|c|}
\hline & \multicolumn{2}{|c|}{ Saprotrophic fungi } & \multicolumn{2}{|c|}{ Pathogenic fungi } & \multicolumn{2}{|c|}{ Arbuscular mycorrhizal fungi } & \multicolumn{2}{|c|}{ Ectomycorrhizal fungi } \\
\hline & Model & Variance & Model & Variance & Model & Variance & Model & Variance \\
\hline & \multirow[t]{2}{*}{ Plot location } & $16 \%$ & Location & $2 \%$ & Location & $3 \%$ & Plot location & $14 \%$ \\
\hline & & & Tree comp & $5 \%$ & Tree comp & $2 \%$ & $\begin{array}{c}\text { Sample tree ID } \\
\text { Sample tree } \\
\text { AM/EcM type } \\
\text { EcM tree abundance* }\end{array}$ & $11 \%$ \\
\hline & $\begin{array}{l}C_{\text {tot }} \\
\text { CN } \\
\text { CEC } \\
\text { BS } \\
\text { SWC }\end{array}$ & $19 \%$ & $\mathrm{CN}$ & $9 \%$ & $\begin{array}{c}\mathrm{pH} \\
\mathrm{CN} \\
\mathrm{CEC}\end{array}$ & $22 \%$ & & \\
\hline$R^{2}, P$ & $54 \%$ & 0.0001 & $23 \%$ & 0.0001 & $43 \%$ & 0.0001 & $26 \%$ & 0.0001 \\
\hline
\end{tabular}

to hamper fine root growth and nutrient acquisition by trees (Marschner, 1991; Kinraide, 2008; de Wit et al., 2010). The detectable decrease in tree fitness due to metal toxicity might have led to fewer resources being translocated to the mycorrhizal fungal partner and fewer colonization sites due to negative impacts on root structure. None of the topographic variables and abiotic soil properties analyzed correlated with plant pathogen fungal richness. This could be due to the primary dependency of the pathogenic fungi on the living plant tissue. However, many pathogens spend their lifecycle partly as saprotrophs and thus a correlation with abiotic soil properties would have been expected (Kabbage et al., 2015).

None of the fungal groups analyzed, saprotrophs, pathogens, AM or EcM fungi, showed significant correlations between species richness and tree diversity. Similarly, no causal relationship of fungal richness and richness of fungal functional groups with plant diversity was found in a global study by Tedersoo et al. (2014). Only ectomycorrhizal fungal richness was globally correlated with the relative proportion and richness of EcM plants. In addition, in a regional study, Tedersoo et al. (2016) concluded that soil resources and tree species identity have greater effects on the diversity of soil biota than tree species richness per se. This is also supported by the observational study of Scheibe et al. (2015) conducted in German temperate broadleaved forests. Specific tree fungal richness relationships were found by Liang et al. (2015) and Nguyen et al. (2016b). Nguyen et al. (2016b) reported, from the American IDENT experimental site, a correlation between EcM fungal richness and plant phylogenetic diversity which was caused by the host specific EcM fungal species associated with gymno- and angiosperms. Several local and regional observational studies have reported strong tree species effects (Urbanova et al., 2015) and a correlation between plant and fungal richness (Gao et al., 2013; Martínez-García et al., 2015). Liang et al. (2015) found a negative relationship between AM fungi and tree diversity in subtropical restoration sites, which was attributed to a (presumably) higher carbon flux to the belowground compartment in less diverse and fast-growing forests compared to diverse but light-limited secondary forests.

We determined fungal richness based on the presence and absence of diagnostic sequences in DNA extracted from bulk soil samples. However, tree community effects might first be discernible in changes in fungal abundances, before fungal species disappear from the detectable soil DNA pool. Fungal species could be detectable for several years through DNA content extracted from inactive spores, dead mycelium and extracellular DNA (Levy-Booth et al., 2007; Nielsen et al., 2007) even when they are not actually living under present-day conditions. Furthermore, plants must be successfully colonized by fungi before differences in their fungal symbionts' efficiency can have any effect (Dickie et al., 2015), so relatively inefficient fungi may reside in habitats spanning fairly wide ranges of environmental conditions for considerable periods. In grassland experiments, time lags of several years were reported before changes in the plant community composition led to detectable changes in the composition of the soil microbial community (Eisenhauer et al., 2010). Thus the effects of tree species identity and tree species richness on fungal richness could still become detectable in future years of forest development. In comparison, the experimental forests in the study of Tedersoo et al. (2016) were well-grown with a closed canopy.

\section{Differences in Tree Community Variables Significantly Affected Community Structure for Fungal Groups Other Than Saprotrophs}

Consistent with their dominant influence on fungal richness, spatial variables and abiotic soil properties also had the strongest effects on fungal community assembly. These variables explained a large proportion of saprotroph beta-diversity without there being any effect of tree related variables. At the time of the study, tree saplings (including many evergreen tree species) provided only limited belowground carbon input through rhizodeposits 
and leaf litter. As saprotrophic fungi depend on dead rather than living plant tissue, this community was likely sustained by the carbon stock residing in stumps and dead roots from the previous forest plantation. Several other studies have also revealed a strong influence of abiotic conditions on saprotroph and whole fungal communities (Wu et al., 2013; Prévost-Bouré et al., 2014; Tedersoo et al., 2014; Pei et al., 2016) while significant impacts of tree species community composition on saprotroph community structure have been found as well (Nguyen et al., 2016b; Schappe et al., 2017). This divergence in results regarding the impact of spatial, biotic and abiotic drivers on soil fungal community composition is also evident from studies focusing on the AM and EcM fungal subgroups (Öpik and Peay, 2016). Many AM fungi are distributed globally (Davison et al., 2015) with global AM fungal diversity (about 300 described to 3000 estimated species, Krüger et al., 2011; Buscot, 2015) being extremely low compared to that of AM host plants (several hundreds of thousands, Wang and Qiu, 2006). The AM fungi have therefore long been thought to be host generalists. Many studies report strong environmental filtering of AM fungal communities by soil properties such as $\mathrm{pH}$ (Dumbrell et al., 2010), distance and CN (Dumbrell et al., 2010; Davison et al., 2016), soil texture and soil moisture (Freitas et al., 2014), and temperature and soil $P$ (Davison et al., 2016). The AM fungal communities in our young subtropical forests were strongly structured by abiotic ( $\mathrm{pH}, \mathrm{CEC}$, and $\mathrm{CN}$ ) and spatial variables. However, several studies found that host plant identity has effects on AM community assembly (Öpik et al., 2009; Wubet et al., 2009; Martínez-García et al., 2015) and it has been suggested that discrete regional and habitat specific fungal pools exist, indicating context dependent host specificity (Öpik and Peay, 2016). We found a significant but weak effect of tree community composition on AM fungal community structure. It should be noted that a rich herb layer, dominated in terms of biomass by ferns, developed at our experimental forest site in addition to the tree saplings planted there (Germany et al., 2017). In Southwest China, Zhang et al. (2004) found that the majority of the fern species they investigated were AM hosts. Substantial amounts of fern-associated AM fungi presumably persisted in the soil and could have impacted the tree-associated AM fungal community composition that we identified and potential relationships with tree variable effects.

The evolutionary development of EcM fungi from white and brown rot fungi took place convergently multiple times during the past 125 million years, reaching an EcM fungal species diversity approximately equal to that of EcM host plants (about 6000, Buscot, 2015). Thus EcM fungi have been assumed to be specific in nature (Öpik and Peay, 2016) and many studies, including our results, support a strong host effect (Ishida et al., 2007; Tedersoo et al., 2008, 2010; Ding et al., 2011). The linkage between tree and EcM communities, together with the high diversity of EcM fungi found, presumably reflects an early stage in the establishment of a complete EcM fungal community at our experimental site. However, the true host preference of EcM fungi may rely causally on the specific environmental conditions created by the host (Öpik and Peay, 2016), since strong environmental drivers of EcM community composition have been reported previously (Huang et al., 2014;
Glassman et al., 2017; van der Linde et al., 2018), to the extent that EcM species can be indicators for key environmental variables (van der Linde et al., 2018). At our site, spatial and tree related variables structured EcM community composition while abiotic soil properties did not. Pathogenic fungal community composition was related to tree community structure, spatial and abiotic variables (CN content). The simultaneous lack of host effects (as indicated by a lack of correlation with differences in tree species identity) could indicate that local tree diversity and non-host neighboring tree species have played prominent roles. A similar pattern was found for biotrophic foliar pathogens in a young temperate experimental forest (Hantsch et al., 2014). Hantsch et al. (2014) concluded that particular non-host species (fast growing conifers in their study) in the vicinity of a target tree species (Tilia cordata and Quercus petraea) may impede or facilitate fungal pathogen infection depending on the identity of the species and its proportion in the local neighborhood.

A large proportion of the variation in fungal community structure and richness remained unexplained by the variables that we studied. There are numerous possible reasons for this finding (Bahram et al., 2015). Some significant effects may have been missed, because influential environmental variables were not measured. For example, Tedersoo et al. (2016) found herb cover and tree basal area to be strongly associated with fungal richness. These variables were not quantified within the framework of our study. In addition, manganese was present in high concentrations, and this has been reported to have a negative influence on tree height (Scholten et al., 2017) and potentially also to have a negative impact on EcM fungal diversity (Huang et al., 2014). However, stochastic processes may also have major effects on fungal community assembly (Powell et al., 2015; Bahram et al., 2016). Furthermore, our sequence-based data on fungal community composition may be insufficiently precise and representative, and this would certainly account for most of the unexplained variation.

\section{CONCLUSION}

We quantitatively assessed the independent contributions made by spatial, abiotic (soil properties and topography) and biotic (tree community structure) variables to soil fungal community structure in a study facilitated by the experimental set-up of the tree diversity forest plots that we investigated. Our results suggest that strong environmental filtering and dispersal limitation were the most important drivers of fungal community assembly in young subtropical forests. The influence of biotic tree community variables could already be detected in mycorrhizal and pathogen fungal groups. Due to the limited size of the tree saplings and thus of the carbon input to the ecosystem by rhizodeposits and leaf litter, we expect there to be increasingly strong tree related effects on fungal community composition as forest development proceeds. Despite focusing on an early stage of forest development, our study clearly indicates that different functional groups of soil fungi respond specifically to different soil and vegetation variables, and that these specific responses may be at either the species richness or the community 
composition level. Ongoing studies on context-dependent community assembly of soil fungi should therefore take into account functional guilds within the fungi.

\section{DATA AVAILABILITY}

Relevant materials and protocols will be made available upon request. Datasets of the raw sequences generated for this study can be found in the European Nucleotide Archive (https://www. ebi.ac.uk/ena/data/view/PRJEB12020) (Weißbecker et al., 2016). The bioinformatically processed sequence dataset and metadata can be found in the Zenodo repository (https://zenodo.org/ record/1215505) (Weißbecker et al., 2018), as can the R scripts generated for the statistical analyses (https://zenodo.org/record/ 1401839) (Weißbecker and Wubet, 2018).

\section{AUTHOR CONTRIBUTIONS}

$\mathrm{CW}, \mathrm{FB}, \mathrm{TW}$, and $\mathrm{HB}$ designed the study. CW performed the soil sampling and sample preparation. TS and PK provided soil measurements. GL, TW, and CW performed the bioinformatics analysis. CW and TW did the statistical analyses. CW, TW, FB, and $\mathrm{HB}$ outlined the manuscript, the first draft was written by CW. All authors contributed to revisions.

\section{FUNDING}

This work was supported by the German Research Foundation (DFG) within the framework of the Research Unit FOR 891

\section{REFERENCES}

Augusto, L., Ranger, J., Binkley, D., and Rothe, A. (2002). Impact of several common tree species of European temperate forests on soil fertility. Ann. For. Sci. 59, 233-253. doi: 10.1051/forest:2002020

Ayres, E., Steltzer, H., Berg, S., Wallenstein, M. D., Simmons, B. L., and Wall, D. H. (2009). Tree species traits influence soil physical, chemical, and biological properties in high elevation forests. PLoS One 4:e5964. doi: 10.1371/journal. pone.0005964

Bahram, M., Kohout, P., Anslan, S., Harend, H., Abarenkov, K., and Tedersoo, L. (2016). Stochastic distribution of small soil eukaryotes resulting from high dispersal and drift in a local environment. ISME J. 10, 885-896. doi: 10.1038/ ismej.2015.164

Bahram, M., Peay, K. G., and Tedersoo, L. (2015). Local-scale biogeography and spatiotemporal variability in communities of mycorrhizal fungi. New Phytol. 205, 1454-1463. doi: 10.1111/nph.13206

Baldrian, P., Kolarik, M., Stursova, M., Kopecky, J., Valaskova, V., Vetrovsky, T., et al. (2012). Active and total microbial communities in forest soil are largely different and highly stratified during decomposition. ISME J. 6, 248-258. doi: 10.1038 /ismej.2011.95

Barton, K. (2018). MuMIN: Multi-Model Inference. R software package.

Bates, D., Mächler, M., Bolker, B., and Walker, S. (2015). Fitting linear mixed-effects models using lme4. J. Stat. Softw. 67, 1-48. doi: 10.18637/jss.v067.i01

Berruti, A., Desiro, A., Visentin, S., Zecca, O., and Bonfante, P. (2017). ITS fungal barcoding primers versus 18S AMF-specific primers reveal similar AMF-based diversity patterns in roots and soils of three mountain vineyards. Environ. Microbiol. Rep. 9, 658-667. doi: 10.1111/1758-2229.12574

Bissinger, V., and Kolditz, O. (2008). Helmholtz Interdisciplinary Graduate School for Environmental Research (HIGRADE), GAIA - Ecological
'BEF-China' [Grant Nos. BU 941/12-2 and BR1698/10-2], a summer school financed by the Sino-German Center [GZ 785], and the Helmholtz Impulse and Networking Fund through the Helmholtz Interdisciplinary Graduate School for Environmental Research (HIGRADE) (Bissinger and Kolditz, 2008).

\section{ACKNOWLEDGMENTS}

We thank participants in the BEF-China project for their support, especially Xuefei Yang, Sabine Both, Bo Yang, and Lin Chen for their help in establishing the project and field site laboratory, as well as their assistance in fieldwork coordination, and Gunnar Seidler who composed the randomized field sampling maps and three-dimensional landscape graphic. For the field sampling we greatly appreciate the help of Zhiqin Pei and the hard work of local employees Zhanhong Qi, Yongxing Qi, and Shilin Qi. Beatrix Schnabel, Melanie Günther, and Sigrid Härtling provided excellent assistance with 454 pyrosequencing. We appreciate the valuable suggestions made by Jonathan Chase, Kenneth Wasmund, Anna Heintz-Buschart and three reviewers who read an earlier version of this manuscript.

\section{SUPPLEMENTARY MATERIAL}

The Supplementary Material for this article can be found online at: https://www.frontiersin.org/articles/10.3389/fmicb. 2018.02312/full\#supplementary-material

Perspectives for Science and Society (Munich: Oekom-Verlag), 17, 71-73. doi: 10.14512/gaia.17.1.16

Blackwell, M. (2011). The fungi: 1, 2, 3.. 5.1 million species? Am. J. Bot. 98, 426-438. doi: $10.3732 /$ ajb. 1000298

Boyer, F., Mercier, C., Bonin, A., Le Bras, Y., Taberlet, P., and Coissac, E. (2016). obitools: a unix-inspired software package for DNA metabarcoding. Mol. Ecol. Resour. 16, 176-182. doi: 10.1111/1755-0998. 12428

Bruelheide, H., Nadrowski, K., Assmann, T., Bauhus, J., Both, S., Buscot, F., et al. (2014). Designing forest biodiversity experiments: general considerations illustrated by a new large experiment in subtropical China. Methods Ecol. Evol. 5, 74-89. doi: 10.1111/2041-210X.12126

Bruns, T. D., and Shefferson, R. P. (2004). Evolutionary studies of ectomycorrhizal fungi: recent advances and future directions. Can. J. Bot. 82, 1122-1132. doi: 10.1139/b04-021

Bünemann, E. K., Bongiorno, G., Bai, Z., Creamer, R. E., De Deyn, G., De Goede, R., et al. (2018). Soil quality - A critical review. Soil Biol. Biochem. 120, 105-125. doi: 10.1016/j.soilbio.2018.01.030

Buscot, F. (2015). Implication of evolution and diversity in arbuscular and ectomycorrhizal symbioses. J. Plant Physiol. 172, 55-61. doi: 10.1016/j.jplph. 2014.08.013

Condit, R., Engelbrecht, B. M. J., Pino, D., Pérez, R., and Turner, B. L. (2013). Species distributions in response to individual soil nutrients and seasonal drought across a community of tropical trees. Proc. Natl. Acad. Sci. U.S.A. 110, 5064-5068. doi: 10.1073/pnas.1218042110

Davison, J., Moora, M., Jairus, T., Vasar, M., Öpik, M., and Zobel, M. (2016). Hierarchical assembly rules in arbuscular mycorrhizal (AM) fungal communities. Soil Biol. Biochem. 97, 63-70. doi: 10.1016/j.soilbio.2016. 03.003 
Davison, J., Moora, M., Öpik, M., Adholeya, A., Ainsaar, L., Bâ, A., et al. (2015). Global assessment of arbuscular mycorrhizal fungus diversity reveals very low endemism. Science 349, 970-973. doi: 10.1126/science.aab1161

de Wit, H. A., Eldhuset, T. D., and Mulder, J. (2010). Dissolved Al reduces $\mathrm{Mg}$ uptake in Norway spruce forest: results from a long-term field manipulation experiment in Norway. For. Ecol. Manag. 259, 2072-2082. doi: 10.1016/j.foreco. 2010.02.018

Dickie, I. A., Alexander, I., Lennon, S., Öpik, M., Selosse, M. A., van Der Heijden, M. G. A., et al. (2015). Evolving insights to understanding mycorrhizas. New Phytol. 205, 1369-1374. doi: 10.1111/nph.13290

Ding, Q., Liang, Y., Legendre, P., He, X., Pei, K., Du, X., et al. (2011). Diversity and composition of ectomycorrhizal community on seedling roots: the role of host preference and soil origin. Mycorrhiza 21, 669-680. doi: 10.1007/s00572-0110374-2

Dumbrell, A. J., Nelson, M., Helgason, T., Dytham, C., and Fitter, A. H. (2010). Relative roles of niche and neutral processes in structuring a soil microbial community. Int. Soc. Microb. Ecol. J. 4, 337-345.

Edgar, R. C., Haas, B. J., Clemente, J. C., Quince, C., and Knight, R. (2011). UCHIME improves sensitivity and speed of chimera detection. Bioinformatics 27, 2194-2200. doi: 10.1093/bioinformatics/btr381

Eisenhauer, N., Bessler, H., Engels, C., Gleixner, G., Habekost, M., Milcu, A., et al. (2010). Plant diversity effects on soil microorganisms support the singular hypothesis. Ecology 91, 485-496. doi: 10.1890/08-2338.1

Floudas, D., Binder, M., Riley, R., Barry, K., Blanchette, R. A., Henrissat, B., et al. (2012). The paleozoic origin of enzymatic lignin decomposition reconstructed from 31 fungal genomes. Science 336, 1715-1719. doi: 10.1126/science.1221748

Fox, J., and Weisberg, S. (2011). An $\{R\}$ Companion to Applied Regression. Thousand Oaks CA: Sage.

Freitas, R. D., Buscardo, E., Nagy, L., Maciel, A. B. D., Carrenho, R., and Luizao, R. C. C. (2014). Arbuscular mycorrhizal fungal communities along a pedohydrological gradient in a Central Amazonian terra firme forest. Mycorrhiza 24, 21-32. doi: 10.1007/s00572-013-0507-x

Gao, C., Shi, N., Liu, Y., Peay, K. G., Zheng, Y., Ding, Q., et al. (2013). Host plant genus-level diversity is the best predictor of ectomycorrhizal fungal diversity in a Chinese subtropical forest. Mol. Ecol. 22, 3403-3414. doi: 10.1111/mec.12297

Gao, C., Zhang, Y., Shi, N.-N., Zheng, Y., Chen, L., Wubet, T., et al. (2015). Community assembly of ectomycorrhizal fungi along a subtropical secondary forest succession. New Phytol. 205, 771-785. doi: 10.1111/nph.13068

Gardes, M., and Bruns, T. D. (1993). ITS primers with enhanced specificity for Basidiomycetes - Application to the identification of mycorrhizae and rusts. Mol. Ecol. 2, 113-118. doi: 10.1111/j.1365-294X.1993.tb00005.x

Gaspar, J. M., and Thomas, W. K. (2015). FlowClus: efficiently filtering and denoising pyrosequenced amplicons. BMC Bioinformatics 16:105. doi: 10.1186/ s12859-015-0532-1

Germany, M. S., Bruelheide, H., and Erfmeier, A. (2017). Limited tree richness effects on herb layer composition, richness and productivity in experimental forest stands. J. Plant Ecol. 10, 190-200. doi: 10.1093/jpe/rtw109

Gilbert, G. S. (2002). Evolutionary ecology of plant diseases in natural ecosystems. Annu. Rev. Phytopathol. 40, 13-43. doi: 10.1146/annurev.phyto.40.021202. 110417

Glassman, S. I., Wang, I. J., and Bruns, T. D. (2017). Environmental filtering by $\mathrm{pH}$ and soil nutrients drives community assembly in fungi at fine spatial scales. Mol. Ecol. 26, 6960-6973. doi: 10.1111/mec.14414

Goslee, S. C., and Urban, D. L. (2007). The ecodist package for dissimilarity-based analysis of ecological data. J. Stat. Softw. 22, 1-19. doi: 10.18637/jss.v022.i07

Grossman, J. J., Vanhellemont, M., Barsoum, N., Bauhus, J., Bruelheide, H., Castagneyrol, B., et al. (2018). Synthesis and future research directions linking tree diversity to growth, survival, and damage in a global network of tree diversity experiments. Environ. Exp. Bot. 152, 68-89. doi: 10.1016/j.envexpbot. 2017.12.015

Hantsch, L., Bien, S., Radatz, S., Braun, U., Auge, H., and Bruelheide, H. (2014). Tree diversity and the role of non-host neighbour tree species in reducing fungal pathogen infestation. J. Ecol. 102, 1673-1687. doi: 10.1111/1365-2745.12317

Huang, J., Nara, K., Zong, K., Wang, J., Xue, S., Peng, K., et al. (2014). Ectomycorrhizal fungal communities associated with Masson pine (Pinus massoniana) and white oak (Quercus fabri) in a manganese mining region in Hunan Province, China. Fungal Ecol. 9, 1-10. doi: 10.1016/j.funeco.2014. 01.001
Humphreys, C. P., Franks, P. J., Rees, M., Bidartondo, M. I., Leake, J. R., and Beerling, D. J. (2010). Mutualistic mycorrhiza-like symbiosis in the most ancient group of land plants. Nat. Commun. 1:103.

Ishida, T. A., Nara, K., and Hogetsu, T. (2007). Host effects on ectomycorrhizal fungal communities: insight from eight host species in mixed coniferbroadleaf forests. New Phytol. 174, 430-440. doi: 10.1111/j.1469-8137.2007. 02016.x

IUSS Working Group WRB (2014). World Reference Base for Soil Resources, International Soil Classification System for Naming Soils and Creating Legends for Soil Maps. Rome: World Soil Resources Reports.

Kabbage, M., Yarden, O., and Dickman, M. B. (2015). Pathogenic attributes of Sclerotinia sclerotiorum: switching from a biotrophic to necrotrophic lifestyle. Plant Sci. 233, 53-60. doi: 10.1016/j.plantsci.2014.12.018

Kinraide, T. B. (2008). Toxicity factors in acidic forest soils: attempts to evaluate separately the toxic effects of excessive $\mathrm{Al} 3+$ and $\mathrm{H}+$ and insufficient $\mathrm{Ca} 2+$ and $\mathrm{Mg} 2+$ upon root elongation. Eur. J. Soil Sci. 54, 323-333. doi: 10.1046/j. 1365-2389.2003.00538.x

Kõljalg, U., Nilsson, R. H., Abarenkov, K., Tedersoo, L., Taylor, A. F. S., Bahram, M., et al. (2013). Towards a unified paradigm for sequence-based identification of fungi. Mol. Ecol. 22, 5271-5277. doi: 10.1111/mec.12481

Krüger, M., Krüger, C., Walker, C., Stockinger, H., and Schüßler, A. (2011). Phylogenetic reference data for systematics and phylotaxonomy of arbuscular mycorrhizal fungi from phylum to species level. New Phytol. 193, 970-984. doi: 10.1111/j.1469-8137.2011.03962.x

Legendre, P., and De Cáceres, M. (2013). Beta diversity as the variance of community data: dissimilarity coefficients and partitioning. Ecol. Lett. 16, 951-963. doi: 10.1111/ele.12141

Legendre, P., Mi, X., Ren, H., Ma, K., Yu, M., Sun, I.-F., et al. (2009). Partitioning beta diversity in a subtropical broad-leaved forest of China. Ecology 90, 663-674. doi: 10.1890/07-1880.1

Levy-Booth, D. J., Campbell, R. G., Gulden, R. H., Hart, M. M., Powell, J. R., Klironomos, J. N., et al. (2007). Cycling of extracellular DNA in the soil environment. Soil Biol. Biochem. 39, 2977-2991. doi: 10.1016/j.soilbio.2007. 06.020

Li, Y., Härdtle, W., Bruelheide, H., Nadrowski, K., Scholten, T., Von Wehrden, H., et al. (2014). Site and neighborhood effects on growth of tree saplings in subtropical plantations (China). For. Ecol. Manag. 327, 118-127. doi: 10.1016/j. foreco.2014.04.039

Liang, Y., He, X., Chen, C., Feng, S., Liu, L., Chen, X., et al. (2015). Influence of plant communities and soil properties during natural vegetation restoration on arbuscular mycorrhizal fungal communities in a karst region. Ecol. Eng. 82, 57-65. doi: 10.1016/j.ecoleng.2015.04.089

Lincoln, N., Chadwick, O., and Vitousek, P. (2014). Indicators of soil fertility and opportunities for precontact agriculture in Kona, Hawai'i. Ecosphere 5:42. doi: 10.1890/ES13-00328.1

Marschner, H. (1991). Mechanisms of adaptation of plants to acid soils. Plant Soil 134, 1-20. doi: 10.1007/BF00010712

Martínez-García, L. B., Richardson, S. J., Tylianakis, J. M., Peltzer, D. A., and Dickie, I. A. (2015). Host identity is a dominant driver of mycorrhizal fungal community composition during ecosystem development. New Phytol. 205, 1565-1576. doi: 10.1111/nph.13226

McMurdie, P. J., and Holmes, S. (2013). phyloseq: an R package for reproducible interactive analysis and graphics of microbiome census data. PLoS One 8:e61217. doi: 10.1371/journal.pone.0061217

McMurdie, P. J., and Holmes, S. (2014). Waste not, want not: why rarefying microbiome data is inadmissible. PLoS Comput. Biol. 10:e1003531. doi: 10.1371/ journal.pcbi.1003531

Nakagawa, S., Schielzeth, H., and O'hara, R. B. (2013). A general and simple method for obtaining R2 from generalized linear mixed-effects models. Methods Ecol. Evol. 4, 133-142. doi: 10.1111/j.2041-210x.2012.00261.x

Nakazawa, M. (2014). fmsb: Functions for Medical Statistics Book with some Demographic Data. R software package.

Nguyen, N. H., Song, Z. W., Bates, S. T., Branco, S., Tedersoo, L., Menke, J., et al. (2016a). FUNGuild: an open annotation tool for parsing fungal community datasets by ecological guild. Fungal Ecol. 20, 241-248. doi: 10.1016/j.funeco. 2015.06.006

Nguyen, N. H., Williams, L. J., Vincent, J. B., Stefanski, A., Cavender-Bares, J., Messier, C., et al. (2016b). Ectomycorrhizal fungal diversity and saprotrophic 
fungal diversity are linked to different tree community attributes in a field-based tree experiment. Mol. Ecol. 25, 4032-4046. doi: 10.1111/mec.13719

Nielsen, K. M., Johnsen, P. J., Bensasson, D., and Daffonchio, D. (2007). Release and persistence of extracellular DNA in the environment. Environ. Biosafety Res. 6, 37-53. doi: 10.1051/ebr:2007031

Oksanen, J., Blanchet, F. G., Kindt, R., Legendre, P., Minchin, P. R., O’hara, R. B., et al. (2013). vegan: Community Ecology Package. R software package.

Öpik, M., Metsis, M., Daniell, T. J., Zobel, M., and Moora, M. (2009). Large-scale parallel 454 sequencing reveals host ecological group specificity of arbuscular mycorrhizal fungi in a boreonemoral forest. New Phytol. 184, 424-437. doi: 10.1111/j.1469-8137.2009.02920.x

Öpik, M., and Peay, K. G. (2016). Mycorrhizal diversity: diversity of host plants, symbiotic fungi and relationships. Fungal Ecol. 24, 103-105. doi: 10.1016/j. funeco.2016.09.001

Paquette, A., Hector, A., Castagneyrol, B., Vanhellemont, M., Koricheva, J., Scherer-Lorenzen, M., et al. (2018). A million and more trees for science. Nat. Ecol. Evol. 2, 763-766. doi: 10.1038/s41559-018-0544-0

Peay, K. G., Baraloto, C., and Fine, P. V. A. (2013). Strong coupling of plant and fungal community structure across western Amazonian rainforests. Int. Soc. Microb. Ecol. J. 7, 1852-1861. doi: 10.1038/ismej.2013.66

Peay, K. G., Kennedy, P. G., Davies, S. J., Tan, S., and Bruns, T. D. (2010). Potential link between plant and fungal distributions in a dipterocarp rainforest: community and phylogenetic structure of tropical ectomycorrhizal fungi across a plant and soil ecotone. New Phytol. 185, 529-542. doi: 10.1111/j.1469-8137. 2009.03075.x

Pei, Z., Eichenberg, D., Bruelheide, H., Wenzel, K., Kühn, P., Li, Y., et al. (2016). Soil and tree species traits both shape soil microbial communities during early growth of Chinese subtropical forests. Soil Biol. Biochem. 96, 180-190. doi: 10.1016/j.soilbio.2016.02.004

Peres-Neto, P. R., and Jackson, D. A. (2001). How well do multivariate data sets match? The advantages of a Procrustean superimposition approach over the Mantel test. Oecologia 129, 169-178. doi: 10.1007/s004420100720

Pinheiro, J., Bates, D., Debroy, S., Sarkar, D., and Team, R. C. (2017). nlme: Linear and Nonlinear Mixed Effects Models. R software package.

Powell, J. R., Karunaratne, S., Campbell, C. D., Yao, H., Robinson, L., and Singh, B. K. (2015). Deterministic processes vary during community assembly for ecologically dissimilar taxa. Nat. Commun. 6:8444. doi: 10.1038/ncomms 9444

Prévost-Bouré, N. C., Dequiedt, S., Thioulouse, J., Lelièvre, M., Saby, N. P. A., Jolivet, C., et al. (2014). Similar processes but different environmental filters for soil bacterial and fungal community composition turnover on a broad spatial scale. PLoS One 9:e111667. doi: 10.1371/journal.pone.0111667

Prober, S. M., Leff, J. W., Bates, S. T., Borer, E. T., Firn, J., Harpole, W. S., et al. (2015). Plant diversity predicts beta but not alpha diversity of soil microbes across grasslands worldwide. Ecol. Lett. 18, 85-95. doi: 10.1111/ele. 12381

R Core Team (2014). R: A Language and Environment for Statistical Computing. Vienna: R Foundation for Statistical Computing.

Robert, V., Vu, D., Amor, A. B., van de Wiele, N., Brouwer, C., Jabas, B., et al. (2013). MycoBank gearing up for new horizons. IMA Fungus 4, 371-379. doi: 10.5598/imafungus.2013.04.02.16

Rognes, T., Flouri, T., Nichols, B., Quince, C., and Mahé, F. (2016). VSEARCH: a versatile open source tool for metagenomics. PeerJ 4:e2584. doi: 10.7717/peerj. 2584

Schappe, T., Albornoz, F. E., Turner, B. L., Neat, A., Condit, R., and Jones, F. A. (2017). The role of soil chemistry and plant neighbourhoods in structuring fungal communities in three Panamanian rainforests. J. Ecol. 105, 569-579. doi: 10.1111/1365-2745.12752

Scheibe, A., Steffens, C., Seven, J., Jacob, A., Hertel, D., Leuschner, C., et al. (2015). Effects of tree identity dominate over tree diversity on the soil microbial community structure. Soil Biol. Biochem. 81, 219-227. doi: 10.1016/j.soilbio. 2014.11.020

Schloss, P. D., Westcott, S. L., Ryabin, T., Hall, J. R., Hartmann, M., Hollister, E. B., et al. (2009). Introducing mothur: open-source, platform-independent, community-supported software for describing and comparing microbial communities. Appl. Environ. Microbiol. 75, 7537-7541. doi: 10.1128/AEM. 01541-09
Schoch, C. L., Seifert, K. A., Huhndorf, S., Robert, V., Spouge, J. L., Levesque, C. A., et al. (2012). Nuclear ribosomal internal transcribed spacer (ITS) region as a universal DNA barcode marker for Fungi. Proc. Natl. Acad. Sci. U.S.A. 109, 6241-6246. doi: 10.1073/pnas.1117018109

Scholten, T., Goebes, P., Kühn, P., Seitz, S., Assmann, T., Bauhus, J., et al. (2017). On the combined effect of soil fertility and topography on tree growth in subtropical forest ecosystems-a study from SE China. J. Plant Ecol. 10, 111-127. doi: $10.1093 /$ jpe/rtw065

Smith, S. E., and Smith, F. A. (2011). Roles of arbuscular mycorrhizas in plant nutrition and growth: new paradigms from cellular to ecosystem scales. Annu. Rev. Plant Biol. 62, 227-250. doi: 10.1146/annurev-arplant-042110103846

Stockinger, H., Krüger, M., and Schüssler, A. (2010). DNA barcoding of arbuscular mycorrhizal fungi. New Phytol. 187, 461-474. doi: 10.1111/j.1469-8137.2010. 03262.x

Taylor, D. L., Hollingsworth, T. N., Mcfarland, J. W., Lennon, N. J., Nusbaum, C., and Ruess, R. W. (2014). A first comprehensive census of fungi in soil reveals both hyperdiversity and fine-scale niche partitioning. Ecol. Monogr. 84, 3-20. doi: 10.1890/12-1693.1

Tedersoo, L., Bahram, M., Cajthaml, T., Põlme, S., Hiiesalu, I., Anslan, S., et al. (2016). Tree diversity and species identity effects on soil fungi, protists and animals are context dependent. Int. Soc. Microb. Ecol. J. 10, 346-362. doi: 10.1038/ismej.2015.116

Tedersoo, L., Bahram, M., Põlme, S., Kõljalg, U., Yorou, N. S., Wijesundera, R., et al. (2014). Fungal biogeography. Global diversity and geography of soil fungi. Science 346:1256688. doi: 10.1126/science. 1256688

Tedersoo, L., Bahram, M., Toots, M., Diedhiou, A. G., Henkel, T. W., Kjøller, R., et al. (2012). Towards global patterns in the diversity and community structure of ectomycorrhizal fungi. Mol. Ecol. 21, 4160-4170. doi: 10.1111/j.1365-294X. 2012.05602.x

Tedersoo, L., Jairus, T., Horton, B. M., Abarenkov, K., Suvi, T., Saar, I., et al. (2008). Strong host preference of ectomycorrhizal fungi in a Tasmanian wet sclerophyll forest as revealed by DNA barcoding and taxon-specific primers. New Phytol. 180, 479-490. doi: 10.1111/j.1469-8137.2008.02561.x

Tedersoo, L., Sadam, A., Zambrano, M., Valencia, R., and Bahram, M. (2010). Low diversity and high host preference of ectomycorrhizal fungi in Western Amazonia, a neotropical biodiversity hotspot. Int. Soc. Microb. Ecol. J. 4, 465-471. doi: 10.1038/ismej.2009.131

Toju, H., Sato, H., and Tanabe, A. S. (2014). Diversity and spatial structure of belowground plant-fungal symbiosis in a mixed subtropical forest of ectomycorrhizal and arbuscular mycorrhizal plants. PLoS One 9:e86566. doi: 10.1371/journal.pone.0086566

Urbanova, M., Snajdr, J., and Baldrian, P. (2015). Composition of fungal and bacterial communities in forest litter and soil is largely determined by dominant trees. Soil Biol. Biochem. 84, 53-64. doi: 10.1016/j.soilbio.2015.02.011

van der Heijden, M., Martin, F., Selosse, M., and Sanders, I. (2015). Mycorrhizal ecology and evolution: the past, the present, and the future. New Phytol. 205, 1406-1423. doi: 10.1111/nph.13288

van der Linde, S., Suz, L. M., Orme, C. D. L., Cox, F., Andreae, H., Asi, E., et al. (2018). Environment and host as large-scale controls of ectomycorrhizal fungi. Nature 558, 243-258. doi: 10.1038/s41586-018-0189-9

Verheyen, K., Vanhellemont, M., Auge, H., Baeten, L., Baraloto, C., Barsoum, N., et al. (2016). Contributions of a global network of tree diversity experiments to sustainable forest plantations. Ambio 45, 29-41. doi: 10.1007/s13280-0150685-1

Walsh, C., and MacNally, R. (2013). hier.part: Hierarchical Partitioning. R software package.

Wang, B., and Qiu, Y. L. (2006). Phylogenetic distribution and evolution of mycorrhizas in land plants. Mycorrhiza 16, 299-363. doi: 10.1007/s00572-0050033-6

Wang, Q., Garrity, G. M., Tiedje, J. M., and Cole, J. R. (2007). Naïve Bayesian classifier for rapid assignment of rRNA sequences into the new bacterial taxonomy. Appl. Environ. Microbiol. 73, 5261-5267. doi: 10.1128/AEM. 00062-07

Weißbecker, C., Buscot, F., and Wubet, T. (2017). Preservation of nucleic acids by freeze-drying for next generation sequencing analyses of soil microbial communities. J. Plant Ecol. 10, 81-90. doi: 10.1093/jpe/rtw042 
Weißbecker, C., and Wubet, T. (2018). BEF China Fungal Diversity: R Statistic Scripts. Zenodo Data Archive, Version 2. Available at: https:/github.com/cwufz/BEFChina_fungaldiversity/tree/v1.0

Weißbecker, C., Wubet, T., Lentendu, G., and Buscot, F. (2016). BEF China Fungal Diversity: Raw Sequence Data of 454 Fungal ITS Amplicons. European Nucleotide Archive. Available at: https://www.ebi.ac.uk/ena/data/ view/PRJEB12020

Weißbecker, C., Wubet, T., Lentendu, G., Kühn, P., Scholten, T., and Buscot, F. (2018). BEF China Fungal Diversity: Processed 454 ITS Amplicon Sequencing Data and Environmental metadata . Zenodo Data Archive, Version 1. doi: 10. 5281/zenodo.1215505

White, T. J., Bruns, T., Lee, S., and Taylor, J. (1990). "Amplification and direct sequencing of fungal ribosomal RNA genes for phylogenetics," in PCR Protocols A Guide to Methods and Applications, eds M. A. Innis, D. H. Gelfand, J. J. Sninsky, and T. J. White (London: Academic Press, Inc), 315-322.

Wu, Y. T., Wubet, T., Trogisch, S., Both, S., Scholten, T., Bruelheide, H., et al. (2013). Forest age and plant species composition determine the soil fungal community composition in a Chinese subtropical forest. PLoS One 8:e66829. doi: 10.1371/journal.pone.0066829

Wubet, T., Christ, S., Schöning, I., Boch, S., Gawlich, M., Schnabel, B., et al. (2012). Differences in soil fungal communities between European Beech (Fagus sylvatica L.) dominated forests are related to soil and understory vegetation. PLoS One 7:e47500. doi: 10.1371/journal.pone.0047500

Wubet, T., Kottke, I., Teketay, D., and Oberwinkler, F. (2009). Arbuscular mycorrhizal fungal community structures differ between co-occurring tree species of dry Afromontane tropical forest, and their seedlings exhibit potential to trap isolates suited for reforestation. Mycol. Prog. 8, 317-328. doi: 10.1007/ s11557-009-0602-8

Yang, X., Bauhus, J., Both, S., Fang, T., Härdtle, W., Kröber, W., et al. (2013). Establishment success in a forest biodiversity and ecosystem functioning experiment in subtropical China (BEF-China). Eur. J. For. Res. 132, 593-606 doi: 10.1007/s10342-013-0696-z

Zeilinger, S., Gupta, V. K., Dahms, T. E. S., Silva, R. N., Singh, H. B., Upadhyay, R. S., et al. (2016). Friends or foes? Emerging insights from fungal interactions with plants. FEMS Microbiol. Rev. 40, 182-207. doi: 10.1093/femsre/ fuv045

Zemunik, G., Turner, B. L., Lambers, H., and Laliberté, E. (2016). Increasing plant species diversity and extreme species turnover accompany declining soil fertility along a long-term chronosequence in a biodiversity hotspot. J. Ecol. 104, 792-805. doi: 10.1111/1365-2745.12546

Zhan, A., He, S., Brown, E. A., Chain, F. J. J., Therriault, T. W., Abbott, C. L., et al. (2014). Reproducibility of pyrosequencing data for biodiversity assessment in complex communities. Methods Ecol. Evol. 5, 881-890. doi: 10.1111/2041-210X. 12230

Zhang, Y., Guo, L., and Liu, R. (2004). Arbuscular mycorrhizal fungi associated with common pteridophytes in Dujiangyan, southwest China. Mycorrhiza 14, 25-30. doi: 10.1007/s00572-0030272-3

Conflict of Interest Statement: The authors declare that the research was conducted in the absence of any commercial or financial relationships that could be construed as a potential conflict of interest.

Copyright (C) 2018 Weißbecker, Wubet, Lentendu, Kühn, Scholten, Bruelheide and Buscot. This is an open-access article distributed under the terms of the Creative Commons Attribution License (CC BY). The use, distribution or reproduction in other forums is permitted, provided the original author(s) and the copyright owner(s) are credited and that the original publication in this journal is cited, in accordance with accepted academic practice. No use, distribution or reproduction is permitted which does not comply with these terms. 